\title{
Research on the teaching value and teaching strategy of leisure sports Feng Chao
}

\author{
Sports and Physics Department, Mianyang Normal University, 621000, China
}

273529824@qq.com

\begin{abstract}
Leisure sports because of its outstanding expression of modern psychology to leisure forms, participants can enjoy the expression of emotion in leisure sports relaxation, freely, so popular, especially with the pace of reform and opening up in China, has been rapid development in China, especially in youth groups welcome. According to the investigation and analysis of the present situation of leisure sports teaching in normal colleges, orientation, in-depth study of the leisure physical education curriculum in normal university curriculum structure, and teachers and students understanding of leisure sports teaching, mainly for normal university leisure sports teaching curriculum construction, the improvement of teaching method, teaching resources and other aspects of further improvement specific research and exploration. Studies suggest that: leisure sports education in higher normal colleges is necessary considering the actual building personnel training plan, and take as its mission to cultivate social needs talents, change the single sports skills training model for the cultivation of compound talents mode diversity.
\end{abstract}

Keywords: Leisure sports; sports teaching; research value

\section{休闲体育教学价值分析及教学策略研究}

\author{
冯超 \\ 绵阳师范学院体育与健康教育学院, 绵阳, 四川, 中国
}

273529824@qq.com

中文摘要: 休闲体育因其突出以休闲形式表 达现代人心理, 参与者可以在放松、自如的 休闲体育中尽情表达情感, 因而深受大众喜 爱, 特别是随着改革开放脚步进入中国后, 在国内得到了快速发展, 尤其是在青年群体 中深受欢迎。结合对师范院校休闲体育教学 现状的调查与分析, 深入研究了休闲体育课 程在师范大学中的定位、课程设置结构、以 及师生对休闲体育教学的认识, 主要针对师 范大学休闲体育教学课程的建设、教学方法 的改进、教学资源的改进等方面进行更深入
具体的研究和探索。研究认为: 高等师范院 校休闲体育教育有必要结合当前实际建立 人才培养规划, 并把培养社会需求人才作为 己任, 转变单一培养体育技能的模式为培养 多样性复合型人才的模式。

\section{关键词：休闲体育; 体育教学; 价值研究}

\section{1. 休闲体育教学研究的目的与意义}

从休闲体育的发源来看, 它的兴起主要 是源于现代社会经济生活水平提高, 人们闲 
暇时间增多。由于其反映现代人的心理特 征, 符合现代人的心理需要, 因而有效的实 现了情感表达。随着20世纪90年代改革开放 的深入, 休闲体育为大众所接受, 在中国社 会进行快速发展时期。进入 21 世纪, 休闲体 育不仅在社会大众群体中更加普及, 特别是 深受高校青年大学生们喜爱。它摆脱了竞技 体育的束缚, 忽略了竞技体育过于程式化的 表现, 使学生寻找到了另一种释放自我的休 闲体育方式。此外, 这种体育方式表达的休 闲体育形式, 已成为高校休闲体育教育课程 的重要组成部分。在高校广泛开展休闲体育 教学不仅有助于塑造大学生形体, 增进体质 健康, 而且有助于培养良好心态。然而, 在 高校休闲体育教育课程中, 由于休闲体育毕 竟一门起步较晚相对新兴的课程, 在教学实 践中还存在一些不足。本文对高等师范院校 休闲体育教学进行研究, 主要目的在于通过 深入认识高等师范院校开展休闲体育教学 的重要价值, 结合高等师范院校休闲体育教 学优点和存在的不足, 探索符合高等师范院 校现状和实际的休闲体育教学方法, 建立符 合大学生需要的高等师范院校休闲体育教 学内容体系, 从而促进高等师范院校休闲体 育教学的快速、健康发展。

\section{2. 发展休闲体育的价值体现}

在高等师范院校开展休闲体育教学可 以促进大学生形体塑造, 有助于培养学生气 质, 锻炼创新思维。休闲体育教学在高等师 范院校教育中占有重要地位, 这不仅是社会 发展的需要, 也适应了个体发展的需求。对 高等师范院校休闲体育教学进行研究既具 有一定的理论价值, 又具有较强的现实价 值。主要表现在以下几个方面: 将休闲体育 引入高等师范院校教学, 符合时代发展的需 要; 对高等师范院校休闲体育教学进行研 究, 有助于改变课程设置不合理, 休闲体育 教学在高等师范院校呈现地位不清晰, 教学 目标不明确的现状; 研究师范大学休闲体育 教学, 有利于丰富休闲体育课程教学内容与 方法。

时代的发展, 社会的进步, 社会大众对 文化的需求也呈现出多元化发展趋势, 作为 社会文化重要组成部分的休闲体育艺术, 必
然随之朝着多元化的方向发展。深入认识高 等师范院校开展休闲体育教学的价值及价 值体现, 有助于更好地明确高等师范院校开 展休闲体育教学的重要性和必要性, 从而更 加积极的探索有效的教学方法, 推进高等师 范院校休闲体育教学的快速发展和健康发 展。

休闲体育的产生和发展并不是偶然的, 它是社会发展到一定程度, 人们对休闲体育 的需求发生了根本性变化, 在时代条件和环 境土壤的共同孕育下而产生的, 休闲体育的 出现与社会意识形态相呼应, 符合人们的身 心需求、符合社会发展的需要, 因此, 休闲 体育具有鲜明的时代特征。休闲体育无论是 在美学形象方面, 还是动作节奏方面, 都符 合现代人的需求。在美学观点上, 休闲体育 反对僵化、反对程式化、反对因循守旧、反 对脱离现实生活, 在休闲体育表现力方面, 反对形式主义、反对单纯追求技巧, 鼓励勇 于抒发真实情感、鼓励反映实际生活、强调 体育要合乎自然运动法则、合乎现代社会生 活实际, 倡导以乐观向上的心态、宽容大度 的情怀参与休闲体育和发展休闲体育。这与 现代人崇尚自由、求同存异、倡导乐观生活 是完全一致的, 因此, 休闲体育深受现代人 的喜爱。在休闲体育的发展中, 鼓励创编符 合自我的休闲体育形式, 在包容心上可以说 是空前的。休闲体育发展具有开放性, 其开 放程度是竞技体育所不具有的。

休闲体育的自由性和包容性还表现在 其对新与旧的认识上。在休闲体育中, 新与 旧之间不存在是与非的关系, 不一定新的总 比旧的好, 因而不适宜对休闲体育采取是非 曲直判断的方式去鉴赏。当然, 通常情况下, 新的似乎总是比旧的更有趣, 也更容易引人 入胜, 或者说往往更能吸引人们的眼球, 易 于引起人们的注意。于是, 对休闲体育作品, 特别是后休闲体育时期的作品, 由于它们离 传统观念更远了, 我们就更不能用传统的美 学思想去评价了, 即使是审美评价, 鼓励创 新也是很符合时代发展需要的、也是很有必 要的。相对于其他事物而言, 休闲体育的审 美与经济和意识相距要远一些, 对那些休闲 体育新作品, 尤其是学生的体育锻炼, 要不 拘泥于传统价值评判, 应该鼓励创造, 激发 
学生的体育参与热情, 因此, 对于学生的休 闲体育活动, 最好是不要进行价值高低的判 断。随着社会的发展, 休闲体育的概念变得 极其宽泛，甚至在休闲体育参与者的眼里， 人的每个动作, 人的每种行为, 都可以融入 休闲体育。正是由于休闲体育的这种包容 性, 以及休闲体育的大胆突破、敢于追求、 勇于创新的特点, 符合当代社会人们的需 要, 也适应了时代发展的需要, 这也就是休 闲体育深受欢迎、广为接受的原因所在。

随着社会的进步、经济的发展与文化的 提升, 高等学校休闲体育教育无论在指导理 念上还是供需关系上, 都发生了巨大的变 化, 体育功能与社会功能有了更多的外延, 休闲体育课程、休闲体育专业在高等院校的 开设, 不仅涉及到宏观的整个教育系统, 还 涉及微观具体的供需关系等。休闲体育鼓励 探索、鼓励创新, 鼓励创作出具有个性化特 征、能体现个人风格的休闲体育作品。当然, 休闲体育也不是包罗万象、更不是绝对的无 限延展, 休闲体育在内涵上具有包容性, 在 思想上具有开拓性, 但在内容体系上仍然强 调要具有系统性, 要能体现一定的休闲功 能、娱乐功能和健身功能的价值取向。

\section{3. 高校休闲体育教学内容及其价值}

社会是向前发展的, 高等教育尤其是培 养师资和社会休闲体育指导员的高等师范 教育, 必须结合时代发展不断丰富休闲体育 教学的内容, 才能适应社会发展的需要。同 时, 在教学方法上, 不但要考虑具体的教学 内容, 还有针对具有的教学对象进行方法探 索和方法创新。在高等师范院校开展休闲体 育教学的重要价值之一就是能够不断丰富 高校休闲体育教学的内容和休闲体育教学 的方法。时代的发展, 社会的进步, 社会大 众对文化的需求也呈现出多元化发展趋势, 作为社会文化重要组成部分的休闲体育艺 术, 必然随之朝着多元化的方向发展。深入 认识高等师范院校开展休闲体育教学的价 值及价值体现, 有助于更好地明确高等师范 院校开展休闲体育教学的重要性和必要性, 从而更加积极的探索有效的教学方法, 推进 高等师范院校休闲体育教学的快速发展和 健康发展。
由于休闲体育形式的特殊性, 以及其 内涵的丰富性, 在高等师范院校开设休闲体 育专业或者休闲体育课程, 不但有助于提升 大家对休闲体育的认识, 而且可以吸引更多 的人参与到休闲体育学习中来, 从而扩大休 闲体育参与群体。我国的高等师范院校开设 休闲体育教学, 并在休闲体育教学内容不断 吸收新兴休闲体育形式, 不但可以不断丰富 内容休闲体育教学内容和形式, 而且可以为 其他类型的休闲体育教学提供方法借鉴, 更 为重要的是, 在高校这个信息高度密集、文 化积淀较多的平台上, 休闲体育教学可以更 好地发挥大学生视野广阔、思想活跃的优 势。总之, 休闲体育教学在高等教育中的发 展, 可以进一步充实休闲体育教学的内容, 有效地丰富休闲体育教学的方法, 还可以更 好地发挥休闲体育的娱乐功能和教育功用, 对于培养大学生的体育观念、提升大学生的 体育能力、塑造健康的心理和优美的体态都 具有积极而重要的作用。

\section{4. 休闲体育教学方法探索}

休闲体育主张因人而宜, 鼓励根据个 人特征进行动作创造, 鼓励因地制宜地创编 休闲体育动作, 因而可以更好地发挥个人的 特长, 在高校大学生群体中开展休闲体育教 学符合大学生个性发展的需要。在过去, 人 们恪守传统体育题材, 竞技体育充斥了人们 的工作、生活和娱乐的各个方面。随着后来 的发展, 休闲体育的发展, 让人们对体育的 节奏和强度有了新的认识和体验。休闲体 育, 更多的是鼓励自由形式, 认为休闲体育 是生活的一部分, 任何动作都可以成为休闲 体育的一部分, 鼓励运用能够有效锻炼身 体、增进身心健康的休闲体育形式。至此, 休闲体育已经注入了强烈的人文气息。在休 闲体育发展中，偶得成分或者 “偶得动作”, 通常情况下更是有利于锻炼的方式, 这是因 为人类最本能的动作, 当然也就是最自然的 动作。在后现代与休闲体育时代, 休闲体育 的发展, 表现出了终极的人文关怀。因此, 在高等师范院校休闲体育教学中通过这方 面理论学习和实践强化, 有助于发展学生个 性。休闲体育是以人体动作有机结合起来 的, 具有显著的实践性特征, 因而休闲体育 
教学的必然要以训练为主要手段来完成教 学过程和实现教学目标。

\section{1 课堂基础教学}

休闲体育教学是一个系统的过程, 需要 循序渐进, 要从基础教学开始, 在实践训练 中提升学生的能力。通过学习过程让学生掌 握休闲体育技巧, 提升综合能力。在师范院 校休闲体育教学中, 课堂基础教学主要是通 过对休闲体育的学习, 使学生先了解休闲体 育, 为下一步学习打下较为扎实的基础。基 础教学阶段应将重点放在学会休闲体育的 基本原理和健身原则, 通过一些基础性的休 闲体育运动, 让学生建立起休闲体育概念, 逐步加强对自己身体的认识。通过一定时间 阶段的基础性学习, 可以让学生的体育锻炼 热情得到较大程度的提高, 有效提升学生的 体育能力。

\section{2 专业技术训练}

休闲体育作为体育的一种类型, 与其他 各类体育一样具体显著的实践性特征, 因此 技术训练是休闲体育训练的主要方式和直 接手段。休闲体育的技术训练不仅仅是单纯 的身体训练, 在技术训练中, 动作练习本身 就可以提升学生的运动技能、开发学生的身 体潜能, 同时, 学生可以在技术训练中得到 情感体验, 激发其探索身体的运动方式, 从 而激发其深入学习和探索休闲体育的欲望, 进而起到开发其智力的作用。因此, 结合休 闲体育的发展理念和技术特征, 要充分发挥 学生的创造性, 在教学实践中将基础的技术 训练和即兴训练有机的结合起来, 有效提升 技术训练的效率和效果。

\section{3 体育综合训练}

综合训练就是体能、技术、技巧、方法， 以及基本动作、套路的全面训练。休闲体育 是包含多项动作内容和多方面技术动作的 休闲体育, 要让学生在短时间内得到一定的 提升, 并掌握休闲体育动作技巧, 既要采取 专项训练, 基础训练的方法, 又要通过即兴 训练激发学生的创新思维和创新能力, 还要 通过综合训练提升学生的综合素质, 增强休 闲体育运动的综合能力。休闲体育的技术训 练教学中最大的特点是体能训练与风格训
练相融合的综合训练, 即是任何可以解放身 体、增加身体运动能力的练习都可以作为训 练的内容和手段, 从而同时解决体能问题和 健康锻炼问题, 把增加身体肌肉素质能力、 磨练意志力、忍耐力与身心健康有机结合起 来, 进行综合训练。由于休闲体育往往都带 有一定的个性特征, 休闲体育动作通常都是 带有一定的个性色彩的休闲体育元素, 这些 休闲体育元素实际上就是构成休闲体育单 元基本的动作。在休闲体育训练中, 训练过 程往往就是对休闲体育基本元素的强化训 练, 而分解动作的训练往往容易让练习者只 见局部不见整体, 使学生比较茫然, 但如果 通过综合训练, 将分解动作与整体训练和训 练目的相结合, 就可以让学生更好地掌握一 类休闲体育。在具体的休闲体育教学训练实 践中, 要实现 “综合” 的目的和达到 “综合” 的效果, 就需要将二者融合为一体, 教学的 重点是强调身体运动的过程, 训练效果才能 得到体现。

\section{5. 休闲体育课程教学的要点}

休闲体育课程教学主要是通过具体的 休闲体育运动项目, 让学生认识休闲体育, 热爱体育锻炼。结合休闲体育课程教学的特 点, 才能更好地实施教学, 增强课堂组织的 有效性, 提高课程教学效率。

\section{1 身心同步}

休闲体育教学既要培养学生的休闲体 育思想, 又要促进学生的身心健康。强调身 心同步既是休闲体育教学的需求和要求, 也 是休闲体育本质功能的有效发挥。身体本就 是自然产物与文化产物的共同体，而休闲体 育也同样既是社会产物、也是文化产物, 二 者具有天然的同一性。因此, 休闲体育教学 强调身心同步, 是以人为本的具体体现, 是 对休闲体育作用价值的高度认可。“动作起 于心”，休闲体育从产生之处就特别强调以 动作轻松自如、表达真实情感和情绪。休闲 体育的重要特点之一就是让参与者尽情释 放内心的情感, 实现身心合一。

身体姿态、肢体动作，之所以说可以 是一种语言, 是因为它可以传情达意。休闲 体育就其本质而言, 它属于身体运动类型的 
一种形式, 但这种运动形式说承载的却是一 种理念、观念和价值追求, 尤其是在现当代 休闲体育发展中, 休闲体育鲜明的表达了现 代人的休闲娱乐态度。作为一种身体运动形 式, 休闲体育始终是以身体为起点、以肢体 动作为呈现、最终返回身体的原点。

\section{2 培养意识}

休闲体育意识是休闲体育参与者或者 休闲体育教学人员在休闲体育实践活动过 程中通过大脑的积极思维而产生和形成的 一种反映休闲体育思想的自我意识。休闲体 育意识主要包括学生自己对休闲体育各要 素的基本认识, 对身体表现力的认识, 对健 康与休闲体育关系的认识, 对休闲体育表现 情感等的认识, 并通过这些基本的认识来促 进自身参与休闲体育。在休闲体育教学实践 中, 培养休闲体育意识首先要加强休闲体育 认知, 同时要培养感觉能力以及休闲体育热 情的培养。在休闲体育教学中, 教师可以通 过开发休闲体育教学法、休闲体育欣赏等课 程, 并在这些课程中有意识的引导学生如何 学习休闲体育、参与休闲体育, 从内心深处 理解休闲体育, 培养他们的高层次的休闲体 育心理, 这对他们休闲体育意识的培养有很 好的效果。

\section{3 开发潜能}

一个人的休闲体育能力不是天生的, 也 不是一朝一夕可以形成的。尽管人的生理条 件, 尤其是神经系统的特点, 对体育能力的 形成有一定的影响, 但是这种影响比较小。 事实上, 人的体育能力的发展在长期的生活 实践中, 受到体育锻炼实践的影响, 主要来 源于系统性的体育锻炼。休闲体育作为一种 以休闲、娱乐方式达到健身、悦心目的的身 体锻炼方式, 能更好的激活人的心身。休闲 体育的创新发展, 在融合现代主流思想的创 作中, 有助于促进学生潜能的开发。休闲体 育的产生、发展, 是时代精神与康乐体育发 展的需求相适应的产物。它能够通过简单、 直接甚至是随意的肢体动作达到体育锻炼 的效果。因此, 通过休闲体育训练实践和休
闲体育欣赏, 从多方面深入分析休闲体育的 魅力与特点, 并从不同角度欣赏休闲体育, 对于学生潜能开发将有着很大的现实意义。 在休闲体育中, 宽容之心不但可以接纳各种 体育的新形式, 而且可以在动作与环境的综 合作用下获得特殊的感受体验。因此, 不仅 休闲体育锻炼实践可以开发学生潜能, 而且 有思想、有意识、有准备的休闲体育欣赏也 可以开发学生的潜能。

本文通过对休闲体育教学目的意义的 全面认识, 着重分析在高等师范院校强化休 闲体育教学重要价值, 既明确了在高等师范 院校中开设休闲体育课程符合时代发展的 需要, 又提出了高等师范院校休闲体育教学 方法策略。高等师范院校休闲体育教育是培 养符合现代社会发展需要的人才, 有必要结 合当前实际建立人才培养规划, 并把培养社 会需求人才作为己任, 转变单一培养体育技 能的模式为培养多样性复合型人才的模式, 建设起符合社会广泛需求、结构科学合理、 层次多样的教育结构体系。在高等师范教育 中, 如果能够在理论上探索如何有效的将休 闲体育特点与学生群体的特点结合起来, 那 么对于休闲体育教学、训练实践必然有助推 作用, 有助于提高休闲体育教学水平, 从而 提升教学效果。

\section{References}

[1] Liu Qingyi. Leisure sports, Shanghai publishing house, pp. 122-124, 2012.

[2] Lin Rongzhen. North West Fujian leisure sports education in Colleges and universities, Sichuan Normal University, 2008.

[3] Li Xianhua. I see the leisure sports teaching in Higher Teachers Colleges, Shaanxi Education (Higher Education Edition), vol.13, pp. 19-20, 2008.

[4] Huang Wei. Analysis of leisure sports based on recreation, Northeast Normal University, vol. 8, pp.13-14, 2013. 